\title{
Interaction of late pregnancy and lactation in rats
}

\author{
T. R. Koiter, H. Moes, N. Valkhof and S. Wijkstra \\ Division of Reproductive Biology, Department of Obstetrics and Gynaecology, University of Groningen, PO Box: 30001, 9700 RB, \\ Groningen, The Netherlands
}

\begin{abstract}
The effect of pregnancy on lactation was studied during the third week of lactational pregnancy in postpartum pregnant rats with a delay in implantation of only 1 day $(1 \mathrm{~d}-$ LP rats). In an experimental design in which the suckling litter was prevented from consuming solid food, lactational performance was estimated by weighing the ten-pup suckling litters on days 16-21 of lactation or by measuring maternal weight loss after a nursing spell on day 21. In 1d-LP rats, food consumption as well as lactational performance was lower than it was in nonpregnant lactating rats ( $L$ rats) and pregnant-lactating rats with a normal long delay of implantation of at least 6 days (LP rats). The time spent by the pups sucking at the nipples was not different among the three groups, but the number of milk ejections was diminished in 1d-LP dams. Restriction of daily food supply during days 16 to 21 of lactation diminished lactational performance more strongly in 1d-LP rats than it did in L rats; $1 \mathrm{~d}-\mathrm{LP}$ rats conserved protein stores and mobilized fewer minerals than did $\mathrm{L}$ rats. The weight and composition of the litter in utero were not affected by the food restriction. In pregnant-lactating rats (LP and 1d-LP rats), the number of early resorptions was increased in comparison with pregnant rats, showing that lactation can affect the earlier stages of pregnancy. It was concluded that late pregnancy does not affect nursing behaviour, but suppresses lactation by restricting maternal food intake and mobilization of maternal stores. Measurements in serum indicate a causative role for oestradiol, but not for leptin.
\end{abstract}

\section{Introduction}

In eutherian mammals, both pregnancy and lactation pose a heavy strain on maternal metabolism (Gittleman and Thompson, 1988). In Norway rats, the duration of pregnancy (22 days) is short relative to the duration of lactation (about 3 weeks). Like many other rodents, Norway rats can become pregnant again shortly after parturition (Gilbert, 1984). Such postpartum pregnancies of lactating rats last longer than pregnancies of non-lactating rats as a result of a delay in implantation of the blastocysts, the duration of which depends on various factors, including the size of the suckling litter (Mantalenakis and Ketchel, 1966). This delay in implantation prevents the overlap of lactation with the last week of pregnancy, during which the growth of the conceptus accelerates and the energetic demands of pregnancy are increasing rapidly (Morrison, 1956).

During postpartum pregnancy in rats, lactation can be extended artificially by regular replacing of the litter (Paape and Tucker, 1969) or implantation can be advanced by oestrogen treatment (Oswald and McClure, 1987) so that the last week of pregnancy can be made to coincide with lactation. In this situation, suckling litter growth decreases,

Received 2 July 1998 while pregnancy outcome does not appear to be compromised. In the present study, this preponderance of late pregnancy over lactation was investigated.

Lactation induces the mobilization of maternal stores and a large increase in food intake, depending on the size of the suckling litter (Ota and Yokoyama, 1967; Naismith et al., 1982; Young and Rasmussen, 1985). However, pregnancy induces increased fat storage and a moderate increase in food intake (Strubbe and Gorissen, 1980; López-Luna et al., 1991). An experimental design in which only the pregnant-lactating dam had access to solid food was used to investigate whether decreased food intake by the dam may explain the decreased suckling litter growth. The effect of food restriction on growth and body composition of the dam was also investigated to determine whether the preparedness of the pregnantlactating dam to mobilize resources is diminished. In a third experiment, the time spent by the dam suckling the litter was measured to investigate whether nursing behaviour is affected by pregnancy. In the same experiment, lactational performance was quantified and serum concentrations of hormones that may be involved in milk production (such as, prolactin, placental lactogens and the ovarian steroids, progesterone and oestradiol), maternal metabolism (such as, growth hormone (GH) and placental lactogens) and food intake (such as leptin, progesterone and oestradiol) were measured. 


\section{Materials and Methods}

\section{Animals}

Female rats of the local Wistar strain with a 4 day oestrous cycle were kept in macrolon cages (dimensions: $35 \mathrm{~cm} \times$ $25 \mathrm{~cm} \times 15 \mathrm{~cm}$ ) on wood shavings at a temperature of $22 \pm 1^{\circ} \mathrm{C}$ with lights on from $06: 30$ to $17: 30 \mathrm{~h}$. The rats had free access to food and tapwater and food pellets (code 1062; Hope Farms, Woerden) contained $21.4 \%$ digestible protein, $6.2 \%$ fat, $58.5 \%$ carbohydrate, $6.1 \%$ minerals and $4.3 \%$ fibre. The gross energy was $19100 \mathrm{~kJ} \mathrm{~kg}^{-1}$.

Oestrous cyclicity was determined by taking daily vaginal smears. At the age of 3-4 months, 190-240 g rats were housed with fertile males from day 19 until the day after parturition, which was designated day 0 of lactational or postpartum pregnancy. On that day, the litters were standardized to ten pups by adding or removing pups. Lactating control rats were not housed with males and the day after parturition was designated day 0 of lactation.

\section{Experimental design}

These studies were approved by the local committee on animal experiments and were performed in accordance with UK legal requirements.

Experiment 1. Changes in weight of mother and litter and food and water intake were monitored in four groups of rats: (1) Pregnant-lactating rats with a normal long pregnancy, lasting at least 28 days (LP rats; $n=12$ ). (2) Pregnant-lactating rats, in which the prolongation of pregnancy was reduced to about 1 day by temporary removal of the litter (compare with Zeilmaker, 1964), which was placed with a foster mother for $32 \mathrm{~h}$, starting at 09:00 h on day 4 (1d-LP rats; $n=9$ ). The duration of pregnancy in these rats was 23 days (one pregnancy lasted 24 days). (3) Lactating rats, from which the litter was also temporarily removed on day 4 (L rats; $n=7$ ). The results from lactating rats, from which the litter was not removed (LNR rats; $n=16$ ) were indistinguishable from those obtained with $\mathrm{L}$ rats and are not shown. (4) Lactating rats, the litters of which retained free access to solid food (Lchow rats; $n=7$ ).

The food container was placed on top of the cage, out of reach of the suckling pups, so that they were unable to obtain solid food themselves. Thus, maternal food intake and lactational performance, as reflected in the daily weight gain of the suckling litter, could more accurately be determined. The pups retained free access to water. Mothers and litters were weighed between 09:00 and 11:00 h on day 0 and from day 14 (day 13 in P rats) to day 21 (day 20 in P rats), when the pups were removed. Maternal weight and food intake were also measured from day 14 (13) until day 21 (20).

Experiment 2. The effects of food restriction ( $40 \mathrm{~g} \mathrm{day}^{-1}$ from day 16 to day 21) on the weight gains of the mother and the suckling litter were studied in (1) pregnant-lactating rats, from which the litters were temporarily removed on day 4 (R1d-LP rats; $n=6$ ); and (2) lactating rats, from which the litters were removed for $32 \mathrm{~h}$ on day 4 (RL rats; $n=6$ ).

In addition, body composition was determined in R1d-LP rats $(n=6)$ and RL rats $(n=7)$ on day 21 of lactation, as well as in $P$ rats $(n=6)$ on day 20 of pregnancy. For the latter group of rats, $40 \mathrm{~g}$ of food per day is equivalent to ad libitum feeding.

\section{Determination of carcass composition}

The animals were decapitated and the tail and hind paws cut off. The alimentary tract was removed (stomach and intestines), as well as the uterus, which was dissected at the oviduct and the cervix. All fat adhering to these organs was removed and replaced in the carcass. The water, fat, protein and ash content of the eviscerated carcasses and of the uteri of the pregnant dams were determined. Water content was determined by drying for a week at $60^{\circ} \mathrm{C}$. Fat content was determined by extracting the dried carcass with petroleumether in a Soxhlet apparatus. Protein content was determined in duplicate in samples of the finely ground (it had to pass through a sieve with mesh pores of $0.2 \mathrm{~mm}$ ), dried, fat-free carcass by the Kjeldahl method. Ash content was determined in duplicate as the residues of samples of the ground, fatfree, dry carcass after $20 \mathrm{~h}$ at $1000^{\circ} \mathrm{C}$.

Experiment 3. In L and LNR (together $n=10$ ), 1d-LP $(n=7)$ and LP $(n=5)$ rats, lactational behaviour was studied from $08: 30$ to $10: 30 \mathrm{~h}$ and from $16: 30$ to $18: 30 \mathrm{~h}$ on day 19 of lactation and from $00: 30$ to $02: 30 \mathrm{~h}$ on day 20 by determining every minute whether one or more pups were attached to the nipples (van der Schoot et al., 1989). The number of milk ejections during the observation period was recorded by observation of the characteristic stretching behaviour of pups (Wakerley et al., 1994).

In the same animals, tests of lactational performance were performed on day 21 of lactation (van der Schoot et al., 1991). Food, pups and mothers were weighed at $09.00 \mathrm{~h}$ and then placed in separate cages; both dam and pups could drink freely, but only the dam had free access to food. Food, dam and pups were weighed again $6 \mathrm{~h}$ later and dam and litter were placed together. Nursing behaviour was observed and the milk ejections were counted. After $1 \mathrm{~h}$, the dam and the pups were weighed again and the dams were immediately decapitated and trunk blood was gathered for determination of serum concentration of leptin, GH, prolactin, lactogenic activity $\left(L_{\text {act }}\right)$, oestradiol and progesterone. The weight of the carcass and the uterus were measured and the number of fetuses was counted.

\section{Hormone measurements}

Progesterone and oestradiol concentrations were determined by radioimmunoassay. The sensitivity of the progesterone assay was $0.2 \mathrm{nmol}^{-1}$; the intra- and interassay variabilities were $<10 \%$. The sensitivity of the oestradiol assay was $0.02 \mathrm{nmol}^{-1}$ and the intra- and interassay variabilities were $<8 \%$. GH and prolactin were determined 
by double antibody radioimmunoassay, using the antibodies and the standards rGH-RP2 and rPRL-RP-3 provided by the NIDDK. The sensitivities of the assays were $2.0 \mathrm{ng} \mathrm{GH} \mathrm{ml}^{-1}$ and $0.5 \mathrm{ng}$ prolactin $\mathrm{ml}^{-1}$; intra-assay variabilities were 9 and $7 \%$, respectively. All measurements were carried out in a single GH assay; the interassay variability of the prolactin assay was $8 \%$. Rat leptin was determined by means of a radioimmunoassay kit (Linco, St Charles, MO) with a sensitivity of $0.5 \mathrm{ng} \mathrm{ml}^{-1}$ and intra- and interassay variabilities of 5 and 3\%, respectively. Lactogenic activity was determined by bioassay using an $\mathrm{Nb} 2$ Node lymphoma cell line with rPRL-RP-3 as standard (Tanaka et al., 1980). This assay does not measure $\mathrm{rGH}$. All measurements were performed in a single assay. Intra-assay variability was $16 \%$ and the sensitivity $20 \mathrm{pg}$ prolactin $\mathrm{ml}^{-1}$.

\section{Statistical analysis}

Unless otherwise stated, statistical comparisons were made by non-parametric analysis of variance (KruskalWallis test), followed by group-wise comparisons with the Mann-Whitney $U$ test or using Pearson's correlation coefficient. Values were considered significant if $P<0.05$.

\section{Results}

\section{Experiment 1}

Daily food intake and pup growth are shown (Fig. 1a,b). There was no significant correlation between the total food intake of the $1 \mathrm{~d}-\mathrm{LP}$ rats during the last 5 days of lactation and the size of the litter in utero (rho $=-0.026 ; P=0.925 ; n=16$ ). No significant correlation was found on the last day of lactation (rho $=-0.220 ; P=0.412 ; n=16$ ). The food intake of the $P$ and the LP rats also did not correlate with the size of the intra-uterine litter (rho $=-0.089 ; P=0.821 ; n=9$ and rho $=-0.272 ; P=0.327 ; n=15$, respectively).

\section{Experiment 2}

Food restriction suppressed the weight gain of the R1d-LP rats only on the first day (Fig. 2a). The weight gain of the suckling litters of the R1d-LP rats was lower than that of RL rats (Fig. 2b) throughout the experiment. There was a significant (negative) correlation between the weight gain of the suckling litters of R1d-LP rats over the last 4 days of the food restriction period and the size of the intrauterine litter (rho $=-0.825 ; P=0.022 ; n=7$ ).

The carcass weights of the P rats, the R1d-LP rats and the RL rats were different (Table 1). The high carcass weight of the P rats was due mainly to the high fat content. In addition, the ash content of $P$ rats was higher than that of the other groups. However, the protein content of $\mathrm{P}$ rats was not different from that of pregnant lactating rats. The lower carcass weight of the RL rats, as compared with that of the R1d-LP rats, was caused by a proportional lower amount of all constituents: water, fat, protein and ash.
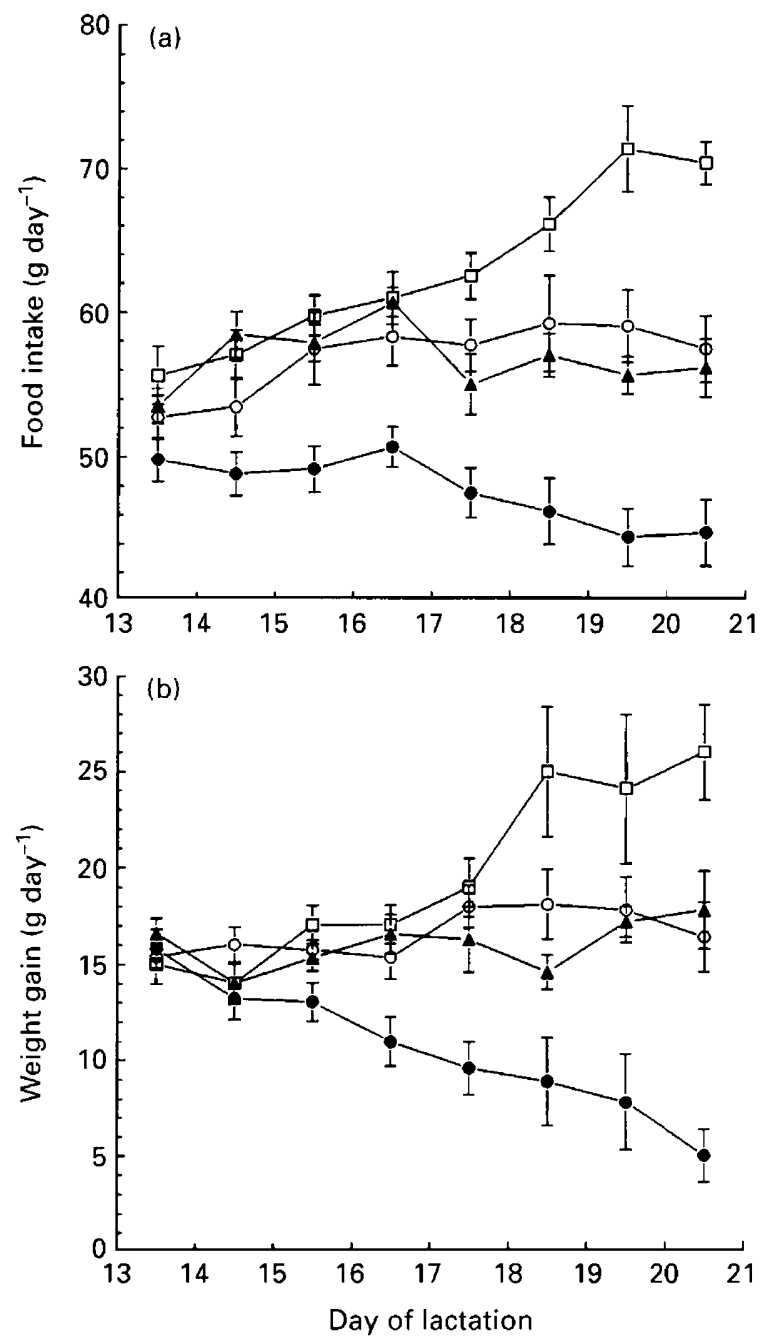

Fig. 1. Daily (a) food intake and (b) weight gain of suckling litters of pregnant-lactating rats with a delay in implantation of 1 day (1d-LP rats; $n=8$ ), of pregnant-lactating rats with a normal delay in implantation of $\geq 6$ days (LP rats; $O ; n=12$ ), of lactating rats (L rats; $\mathbf{\Delta}$; $n=7$ ) and of lactating rats, the litters of which had free access to solid food (Lchow rats; $\square ; n=7$ ) during days $13-21$ of lactation. The rats nursed litters of 10 pups. Means \pm SEM.

Neither the weight $(55.8 \pm 6.5 \mathrm{~g}$ (P rats) versus $48.6 \pm 4.5 \mathrm{~g}$ (R1d-LP rats)) nor the relative water $(87.5 \pm 0.2$ versus $87.3 \pm 0.3 \%$ of body weight), protein $(7.8 \pm 0.2$ versus $7.9 \pm 0.2 \%$ of body weight), fat $(0.75 \pm 0.04$ versus $0.79 \pm 0.03 \%$ of body weight) or ash $(1.06 \pm 0.02$ versus $1.03 \pm 0.02 \%$ of body weight) contents of the gravid uteri of the $P$ rats and the R1d-LP rats were different. The number of live fetuses was the same in P rats $(11.2 \pm 1.3)$ and R1d-LP rats $(10.3 \pm 0.9)$, but the uteri of the $R 1 d$-LP rats contained resorbed fetuses $(1.7 \pm 1.4)$ and the uteri of $P$ rats did not $(0)$ $(P<0.05)$.

\section{Experiment 3}

Maternal behaviour on days 19-20 did not change in the 
Table 1. Carcass weight and composition of lactating (RL) rats and pregnant (P) rats and pregnantlactating rats with a 1 day delay in implantation (R1d-LP) on day 21 of lactation or day 20 of pregnancy

\begin{tabular}{lccc}
\hline & RL rats $(n=7)$ & R1d-LP rats $(n=6)$ & P rats $(n=6)$ \\
\hline Wet carcass weight $(\mathrm{g})$ & $158 \pm 5^{\mathrm{a}}$ & $179 \pm 5^{\mathrm{b}}$ & $213 \pm 7^{\mathrm{c}}$ \\
Water content $(\mathrm{g})$ & $108 \pm 3^{\mathrm{a}}$ & $123 \pm 4^{\mathrm{b}}$ & $129 \pm 4^{\mathrm{b}}$ \\
Fat content $(\mathrm{g})$ & $10.5 \pm 1.4^{\mathrm{a}}$ & $12.9 \pm 1.7^{\mathrm{a}}$ & $36.2 \pm 2.2^{\mathrm{b}}$ \\
Protein content $(\mathrm{g})$ & $31.4 \pm 0.7^{\mathrm{a}}$ & $34.3 \pm 1.1^{\mathrm{b}}$ & $35.7 \pm 1.6^{\mathrm{a}, \mathrm{b}}$ \\
Ash $(\mathrm{g})$ & $4.9 \pm 0.1^{\mathrm{a}}$ & $5.8 \pm 0.1^{\mathrm{b}}$ & $8.0 \pm 1.0^{\mathrm{c}}$ \\
\hline
\end{tabular}

The lactating and pregnant-lactating rats had been subjected to food restriction from day 16 until day 21 of lactation. Within each row data with different superscripts are significantly different $(P<0.05)$.
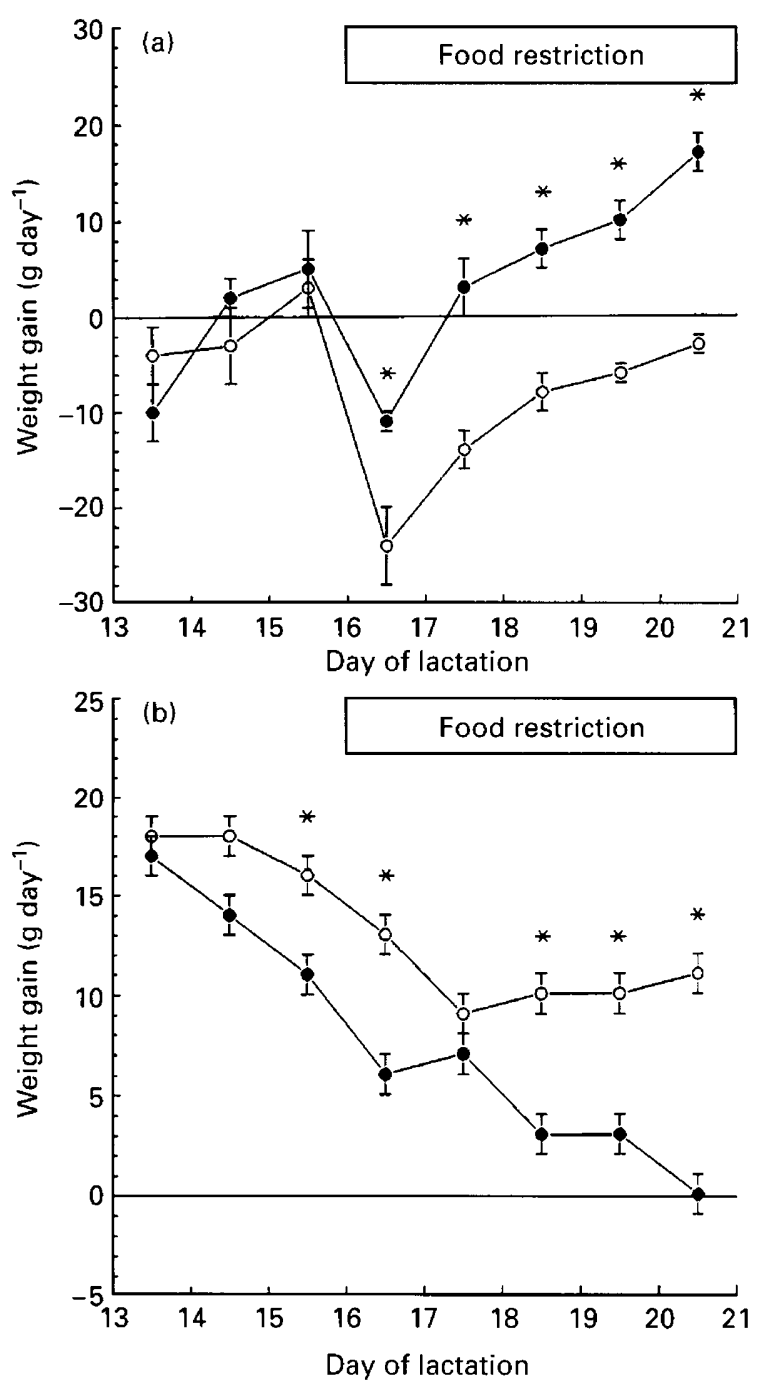

Fig. 2. Daily maternal (a) and suckling litter (b) weight gain of pregnant-lactating rats with a delay in implantation of 1 day $(R 1 d-$ LP rats; $n=6$ ) and lactating rats (RL rats; $O ; n=6$ ) on days $14-21$ of lactation. From day 16 to day 21 of lactation, food was restricted to $40 \mathrm{~g} \mathrm{day}^{-1}$; lactating dams nursed litters of ten pups. Means \pm SEM. ${ }^{*}$ Indicates a statistically significant difference $(P<0.05)$. course of the day, except with regard to feeding frequency: in the morning, $1 \mathrm{~d}-\mathrm{LP}$ rats spent significantly less time feeding $(8.3 \pm 1.8 \mathrm{~min})$ than they did in the night $(16.8 \pm 1.1$ min). The combined results of the three periods are shown (Fig. 3). The pups of the three groups spent a similar amount of time at the nipples of the mother. However, the feeding frequency, the amount of food consumed, litter growth and the number of milk ejections were lower in the 1d-LP group than they were in the other two groups. The reduced number of milk ejections was due to an increased interval between successive milk ejections during a nursing episode ( $3.0 \pm 0.1$ $\min$ for $\mathrm{L}$ rats $(n=141), 3.1 \pm 0.2 \mathrm{~min}$ for LP rats $(n=71)$ and $3.8 \pm 0.3 \mathrm{~min}$ for $1 \mathrm{~d}-\mathrm{LP}$ rats $(n=53))$, and not to a longer delay until the observation of the first ejection of the episode. The mean duration of the nursing episodes, during which milk ejections were observed, was the same for the three groups: $20.4 \pm 1.6 \mathrm{~min}(n=29)$ for $1 \mathrm{~d}-\mathrm{LP}$ rats; $21.7 \pm 1.2 \mathrm{~min}$ ( $n=36)$ for L rats; and $22.1 \pm 1.3 \mathrm{~min}(n=22)$ for LP rats. In addition, the mean duration of the nursing episodes without milk ejections was the same for the three groups: $5.7 \pm 1.0$ $\min (n=36)$ for $1 \mathrm{~d}-\mathrm{LP}$ rats; $4.5 \pm 0.6 \min (n=57)$ for L rats; and $4.0 \pm 0.6 \mathrm{~min}(n=23)$ for LP rats.

The test for lactational performance on day 21 (Fig. 4) showed similar results for all groups but less weight loss in dams in the 1d-LP group. Furthermore, there are statistically significant negative correlations between the number of milk ejections and maternal weight loss during the test (rho $=-0.857 ; P<0.001 ; n=21$ ) and total food intake during the $30 \mathrm{~h}$ preceding the test ( $\mathrm{rho}=0.692 ; P<0.001 ; n=21$ ) of the dam. The carcass weights of the $L$ rats, the $1 \mathrm{~d}-L P$ rats and the LP rats were $192 \pm 7 \mathrm{~g}(n=9), 183 \pm 3 \mathrm{~g}(n=7)$ and $197 \pm 6 \mathrm{~g}(n=4)$, respectively. In the $1 \mathrm{~d}$-LP rats $(n=8)$, $8.9 \pm 1.6$ live fetuses and $2.5 \pm 1.3$ early resorptions were counted (one rat lost all 11 of its conceptuses); in the LP rats $(n=5) 8.8 \pm 2.3$ and $3.0 \pm 2.0$ live fetuses, respectively.

Relative serum concentrations of hormones are shown (Fig. 5). In $\mathrm{L}$ rats, the absolute hormone concentrations were: leptin: $1.84 \pm 0.13 \mathrm{ng} \mathrm{ml}^{-1}$; GH: $10.4 \pm 0.8 \mathrm{ng} \mathrm{ml}^{-1}$; prolactin: $138 \pm 17 \mathrm{ng} \mathrm{ml}^{-1} ; L_{\text {act }}: 117 \pm 15 \mathrm{ng} \mathrm{ml}^{-1}$; oestradiol: $0.09 \pm 0.01 \mathrm{nmol} \mathrm{l}^{-1}$ and progesterone: $64 \pm 21 \mathrm{nmol} \mathrm{l}^{-1}$. The $L_{\text {act }}$ values represent the amounts of prolactin in $\mathrm{L}$ rats. There was a significant correlation between the plasma concentration of oestradiol and lactational performance 


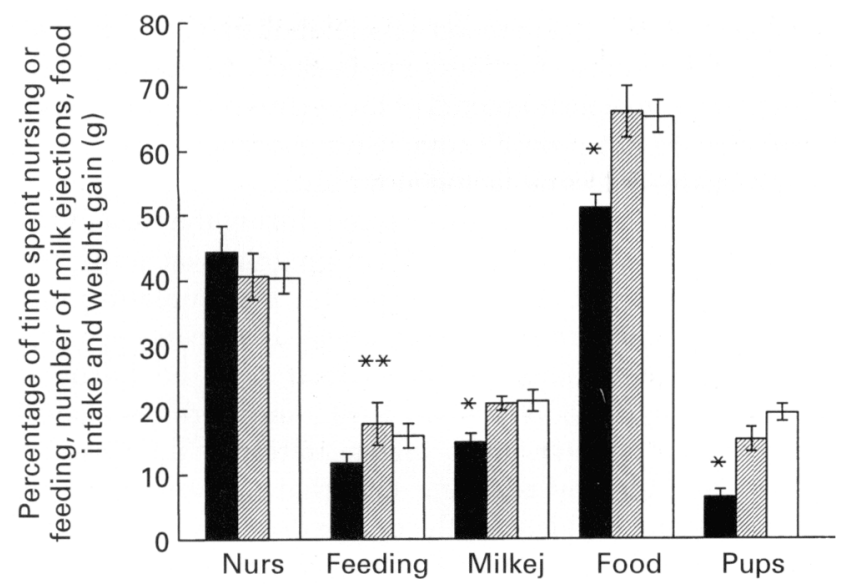

Fig. 3. Percentage of time spent by the rat dam in nursing its litter (Nurs), or in feeding (Feeding), number of milk ejections (Milkej) and food intake (Food) and weight gain of suckling litter (Pups) over $24 \mathrm{~h}$ on days 19-20 of lactation. The dams nursed litters of ten pups. : postpartum pregnant rats with a delay in implantation of 1 day (1d-LP rats) $(n=7) ; \square$ : pregnant-lactating (LP) rats with a normal delay in implantation of $\geq 6$ days $(n=5) ; \square$ : nonpregnant lactating (L) rats $(n=10)$. Means \pm SEM. ${ }^{*}$ Indicates a statistically significant difference from the other two groups; ${ }^{* *}$ indicates a statistically significant difference from the $1 \mathrm{~d}-\mathrm{LP}$ group.

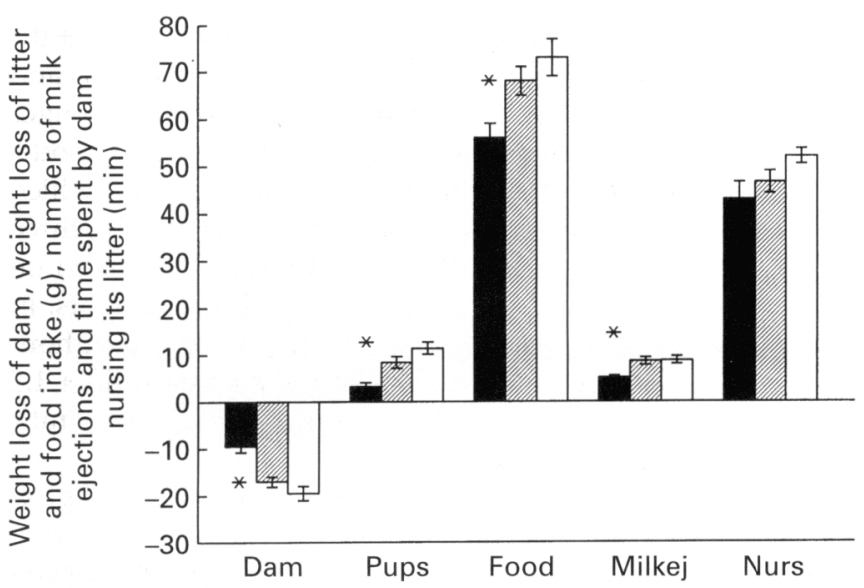

Fig. 4. Weight loss of the lactating rat dam (Dam) and weight gain of suckling litter (Pups) after the $1 \mathrm{~h}$ lactational test on day 21 of lactation and food intake during the $30 \mathrm{~h}$ preceding the test (Food). Time (min) spent by the dam in nursing its litter (Nurs) and number of milk ejections (Milkej) during the test. The dams nursed litters of ten pups. 0 : postpartum pregnant rats with a delay in implantation of 1 day (1d-LP rats); $叉$ : pregnant-lactating (LP) rats with a normal delay in implantation of $\geq 6$ days; $\square$ : nonpregnant lactating (L) rats. Means \pm SEM. *Indicates a statistically significant difference from the other two groups $(P<0.05)$.

(rho $=-0.681 ; P<0.001 ; n=21)$.

\section{Discussion}

The results of the present study show that, in pregnant-

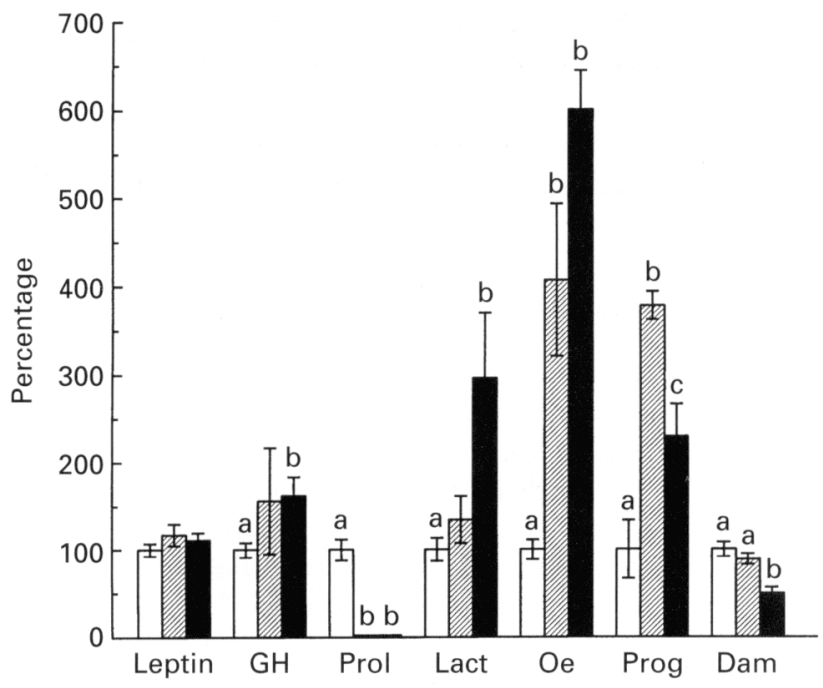

Fig. 5. Percentage changes in leptin, growth hormone (GH), prolactin (Prol), lactogenic activity (Lact), oestradiol (Oe) and progesterone (Prog) immediately after the $1 \mathrm{~h}$ lactational test on day 21 of lactation in nonpregnant lactating (L) rats $(\square)$, pregnantlactating (LP) rats with a normal delay in implantation of $\geq 6$ days ( $\nabla$ ) and postpartum pregnant rats with a delay in implantation of 1 day (1d-LP rats) ( $\square$ ). The weight change of the dams in the course of the test is also depicted (Dam). Means \pm SEM; $L$ rats represent $100 \%$. Dams nursed litters of ten pups. For each group (a versus $b, b$ versus $\mathrm{c}$, and a versus $\mathrm{C}$ ), $P<0.05$.

lactating rats, the decrease in lactational performance during late pregnancy is not due to a change in nursing behaviour of the dam. Rather, it reflects reduced food intake and the adaptation of maternal metabolism to the demands of the litter in utero and, under conditions of reduced food availability, restricted mobilization of protein and mineral stores. Suppression of the milk ejection reflex may play an initiating role and oestradiol may be involved in the causation of these phenomena.

As in lactating rats (Jakubowski and Terkel, 1986), food intake and lactational performance in pregnant-lactating rats reach maxima around days 14-15 of lactation and these amounts are maintained for about a week. Pups start eating solid food around day 17, and this is reflected in increased food consumption and suckling litter growth in the group of lactating Lchow rats, in which the pups had free access to food. However, when pregnancy is in its last week, as is the case in 1d-LP rats, food intake becomes increasingly suppressed. This suppressed food intake by dams may explain the concomitant decrease in pup growth. As food intake was not related to the number of fetuses in utero, this paradoxical effect of pregnancy seems to be related to the pregnant state itself and not to the size of the intrauterine litter.

The similar low carcass weights of the different groups of lactating rats fed ad libitum (L, LP and $1 \mathrm{~d}-\mathrm{LP}$ rats) compared with that of non-lactating pregnant rats ( $\mathrm{P}$ rats) indicate that in pregnant-lactating rats, regardless of the day of implantation, maternal stores are to the same considerable extent mobilized during lactation as they are in lactating rats (Woodside et al., 1981; Glore and Layman, 1985). In 
pregnant-lactating (R1d-LP) rats, if food availability was restricted, protein stores were not depleted even after 5 days, showing that this mobilization concerns only fat and mineral stores. This finding is in contrast to the situation in foodrestricted lactating (RL) rats. Furthermore, in these R1d-LP rats, the food restriction did not induce further mobilization of mineral stores as it did in RL rats. This phenomenon of limited mobilization may have evolved to ensure that sufficient stores are available around parturition since, at this time, the dams will enter a catabolic state because of a decrease in food intake and an increase in energy requirements due to parturition and the initiation of lactation.

The lower growth rates of suckling pups of food-restricted pregnant-lactating R1d-LP rats as compared with those of food-restricted lactating RL rats indicate that factors besides food intake are involved in the reduced suckling litter growth of $1 \mathrm{~d}-\mathrm{LP}$ rats fed ad libitum. The growth of the suckling litters of food-restricted R1d-LP rats was inversely related to the number of live fetuses in utero, which indicates that the conceptus competes directly with the mammary glands for the circulating nutrients. The unimpaired growth of the conceptus not only in the ad libitum fed (1d-LP) rats, but also in food-restricted (R1d-LP rats) pregnant-lactating rats, shows that the mammary glands lose this competition. This finding is in agreement with the observation that, for instance, maternal glucose metabolism is adapted to the pregnant state rather than to the lactational state (Wijkstra et al., 1992).

This complete domination of late pregnancy over lactation is not caused by a change in maternal nursing behaviour. The amount of time spent by the dam nursing its litter is not affected by the presence of a near-term litter in utero, and is in agreement with previous observations of nursing rats towards the end of the third week of lactation (Pfister et al., 1986). The only differences observed were a decrease in food intake during the day and a decrease in the number of milk ejections during nursing episodes in dams carrying a near-term litter.

The number of milk ejections correlated well with food intake, pup growth and, during the test of lactational performance on day 21, with maternal weight loss. A reduced number of otherwise normal milk ejections, driving out normal amounts of milk from the cisternae, may explain the growth retardation of the suckling pups of $1 \mathrm{~d}-\mathrm{LP}$ rats fed ad libitum. It is not clear whether the reduction of the number of milk ejections is the cause or the consequence of the reduced synthesis of milk. There may be a change in the function of the mammary gland. Retarded filling of the alveoli and the mammary ducts owing to the reduced synthesis of milk, may be involved, as the stretch receptors in the gland, which participate in the reflex, would be less stimulated (Wakerley et al., 1994). In addition, the oxytocin release may be suppressed. Tribollet et al. (1978) showed that the interval between successive milk ejections is increased, in the same way as in the present study, by blockade of the $\alpha_{1}$ adrenoreceptors. If such a central effect were involved, it might be hypothesized that the primary change in lactation. is a reduction in number of milk ejections, resulting in decreased emptying of the milk glands, which inhibits the synthesis of milk and, hence, the intake of food.

Changes in the circulating concentrations of various hormones may explain the domination of pregnancy over lactation, as reflected in maternal metabolism (Wijkstra et al., 1992) or the reduced number of milk ejections. Although the present simple measurements of the serum concentrations of hormones do not provide conclusive evidence, members of the prolactin-placental lactogen family may be involved. In rats, prolactin secretion is suppressed during the second half of pregnancy (Voogt et al., 1996). In pregnant-lactating rats, PL can take over the role of prolactin in stimulating milk production (Flietstra and Voogt, 1996). However, increased plasma concentrations of $\mathrm{GH}$, which may be partly of placental origin (Ogilvie et al., 1990), and perhaps also PL (Soares et al., 1991), may affect maternal intermediary metabolism, thereby adapting maternal metabolism to the pregnant state. In this way, the demands of the litter in utero would be met, albeit at the cost of lactational performance.

The serum concentrations of the pregnancy hormone, progesterone, did not show a correlation with lactational performance in the three groups studied. In contrast, oestradiol concentrations, which are increased during the second half of gestation (Bridges, 1984), may have had an effect, as these correlate well with the decrease in lactational performance. Indeed, prolonged exposure to high concentrations of oestrogens causes a decrease in lactational performance and food intake in lactating rats (Fleming, 1976). It is unlikely that the satiety factor, leptin, plays a role in causing the lower food intake of $1 \mathrm{~d}-\mathrm{LP}$ rats. Leptin is produced by adipose tissue and is, at least in rats and mice, produced in proportion to the fat mass (Tritos and Mantzoros, 1997). In the L, LP and 1d-LP rats, adipose tissue was probably depleted to the same extent and leptin concentrations were low in all three groups.

The domination of late pregnancy over lactation has also been recognized in other mammals. For instance, in milk cows, milk yield decreases as gestation proceeds (Olori et al., 1997). In this species, this effect of gestation is without consequences as, under 'natural' conditions, lactation lasts only a few weeks, while gestation lasts for many months. However, in rats, this conflict between lactation and gestation is resolved in another way. During the early stages of pregnancy, the sucking stimulus in combination with high concentrations of prolactin induces a delay in the implantation of the second litter (Flint and Ensor, 1980). The strong sucking stimulus of a large litter may even induce resorption of embryos, shortly after implantation (Veomett and Daniel, 1975; Woodside et al., 1987), as observed in the present study. In this way, the suckling litter no longer has to compete with an intra-uterine litter for limited resources and, thus, the production of consecutive optimally nourished litters with a minimum of delay is ensured.

The authors are much indebted to the late Dr J. Moll, who always showed a lively interest in our research. The carcass composition analysis was performed at the Department of Behavioural Biology (G. J. F. Overkamp) and of Plantecology at the University of Groningen. Lactogenic activities were determined at the Laboratory of Endocrinology and Reproduction, Nijmegen University Hospital (A. Punt-van der Zalm, J. Verbeet and H. J. M. Goverde). The critical comments of $\mathrm{G}$. A. Schuiling are very much appreciated. 


\section{References}

Bridges RS (1984) A quantitative analysis of the roles of dosage, sequence, and duration of estradiol and progesterone exposure in the regulation of maternal behavior in the rat Endocrinology 114 930-940

Fleming AS (1976) Ovarian influences on food intake and body weight regulation in lactating rats Physiology and Behavior 17 1969-1978

Flietstra RJ and Voogt JL (1996) Rat placental lactogens initiate and maintain lactation yet inhibit suckling-induced prolactin release Endocrine 5 103-110

Flint DJ and Ensor DM (1980) Effects of prolactin and the suckling stimulus on implantation and LH secretion in rats Journal of Reproduction and Fertility $58443-448$

Gilbert AN (1984) Postpartum and lactational oestrus: a comparative analysis in rodentia Journal of Comparative Psychology 98 232-245

Gittleman JL and Thompson JL (1988) Energy allocation in mammalian reproduction American Zoologist 28 863-875

Glore SR and Layman DK (1985) Loss of tissues in female rats subjected to food restriction during lactation or during both gestation and lactation Journal of Nutrition 115 233-242

Jakubowski M and Terkel J (1986) Lactational performance, consummatory behavior, and suppression of estrous cyclicity in rats suckling underfed pups Biology of Reproduction 35 119-125

López-Luna P, Maier I and Herrera E (1991) Carcass and tissue fat content in the pregnant rat Biology of the Neonate 60 29-38

Mantalenakis SJ and Ketchel MM (1966) Frequency and extent of delayed implantation in lactating rats and mice Journal of Reproduction and Fertility 12 391-394

Morrison S (1956) The total energy and water metabolism during pregnancy in the rat fournal of Physiology 134 650-664

Naismith DJ, Richardson DP and Pritchard AE (1982) The utilization of protein and energy during lactation in the rat, with particular regard to the use of fat accumulated in pregnancy British Journal of Nutrition 48 433-441

Ogilvie S, Buhi WC, Olson JA and Shiverick KT (1990) Identification of a novel family of growth hormone-related proteins secreted by rat placenta Endocrinology 126 3271-3273

Olori VE, Brotherstone S, Hill WG and McGuirk BJ (1997) Effect of gestation stage on milk yield and composition in Holstein Friesian dairy cattle Livestock Production Science 52 167-176

Oswald C and McClure PA (1987) Energy allocation during concurrent pregnancy and lactation in Norway rats with delayed and undelayed implantation Journal of Experimental Zoology 241 343-357

Ota K and Yokoyama A (1967) Body weight and food consumption of lactating rats nursing various sizes of litters Journal of Endocrinology 38 263-268

Paape MJ and Tucker HA (1969) Mammary nucleic acid, hydroxyproline, and hexosamine of pregnant rats during lactation and post-lactational involution Journal of Dairy Science 52 380-385

Pfister JF, Cramer CP and Blass EM (1986) Suckling in rats extended by continuous living with dams and their preweanling litters Animal Behavior 34 415-420

Soares MJ, Faria TN, Roby KF and Deb S (1991) Pregnancy and the prolactin family of hormones: coordination of anterior pituitary, uterine, and placental expression Endocrine Reviews 12 402-423

Strubbe JH and Gorissen J (1980) Meal patterning in the lactating rat Physiology and Behavior 25 775-777

Tanaka T, Shiu RPC, Gout PW, Beer CT, Noble RT and Friesen HG (1980) A new sensitive and specific bioassay for lactogenic hormones: measurement of prolactin and growth hormone in human serum Journal of Clinical Endocrinology and Metabolism 51 1058-1063

Tribollet E, Clarke G, Dreifuss JJ and Lincoln DW (1978) The role of central adrenergic receptors in the reflex release of oxytocin Brain Rescarch 142 69-84

Tritos NA and Mantzoros CS (1997) Leptin: its role in obesity and beyond Diabetologia 40 1371-1379

Van der Schoot P, Uilenbroek JThJ and Slappendel EJ (1989) Failure of two progesterone antagonists, mifepristone and onapristone, to affect luteal activity in lactating rats Journal of Reproduction and Fertility 87 593-601

Van der Schoot P, Zeegers TA, Muskiet FAJ and Slappendel EJ (1991) Reduction of the intake of food and water is responsible for reduction in litter growth when dams are treated with a progesterone antagonist British Journal of Nutrition 66 17-26

Veomett MJ and Daniel JC, Jr (1975) Termination of pregnancy after accelerated lactation in the rat II. Relationship to number of young, day of pregnancy and length of nursing Journal of Reproduction and Fertility $\mathbf{4 4}$ $513-517$

Voogt JL, Soares MJ, Robertson MC and Arbogast LA (1996) Rat placental lactogen-I abolishes nocturnal prolactin surges in the pregnant rat Endocrine 4 233-238

Wakerley JB, Clarke G and Summerlee AJS (1994) Milk ejection and its control. In The Physiology of Reproduction Vol. 2 pp 1131-1177 Eds E Knobil and JD Neill. Raven Press, New York

Wijkstra S, Moes H and Koiter TR (1992) Metabolism of pregnant-lactating rats is adapted to pregnancy rather than to lactation American Journal of Physiology 263 E766-E771

Woodside B, Cohen LR and Jans JE (1987) Effect of food restriction during concurrent lactation and pregnancy in the rat Physiology and Behavior $\mathbf{4 0}$ 613-615

Woodside B, Wilson R, Chee P and Leon M (1981) Resource partitioning during reproduction in the Norway rat Science 211 76-77

Young CM and Rasmussen KM (1985) Effects of various degrees of chronic dietary restriction in rat dams on reproductive and lactational performance and body composition in dams and their pups American Joumal of Clinical Nutrition 41 979-987

Zeilmaker GH (1964) Quantitative studies on the effect of the suckling stimulus on blastocyst implantation in the rat Acta Endocrinologica 46 483-492 